\title{
The relational patterns of selected factors influencing the EFL college learners' reading comprehension
}

\author{
Nuriyatul Hamidah \\ UIN Maulana Malik Ibrahim Malang \\ nuriyatulhamidahlagi@gmail.com \\ *) correspondence: nuriyatulhamidahlagi@gmail.com
}

\begin{abstract}
Influencing reading, metacognitive awareness, self-efficacy and motivation are considered as the main factor in affecting EFL reading comprehension. Thus, the aim of the present study is to investigate the relational pattern of those selected factors toward EFL reading comprehension and investigates the contribution of each variable. The design is categorized as quantitative study. The subjects of the study consisted of 90 students of the English Letters and Language, Humanity Faculty, UIN Maliki Malang. The instruments used in this study are a test and questionnaires. Moreover, the data are analyzed using multiple regression techniques including a correlation design called Path Analysis. The result of the study has shown that the regression model in the first layer is proven insignificant to the independent variable. The total contribution of all variables in the first layer is $2.5 \%$. While the regression model of second layer is proven significant. The total contribution of all variables in the path diagram in the second layer of this study is $44.86 \%$. Based on the result, it is suggested for the future research to have a research on other factors such as combining affective and cognitive factors while considering students' diversity such proficiency level, personality and gender.
\end{abstract}

Keywords: metacognitive awareness; self-efficacy; motivation; EFL reading comprehension

\section{INTRODUCTION}

Due to the increasing attention to the foreign language acquisition, many researchers have conducted more studies on this field. Having specifically on language input as well as language output, researchers found out that there are factors that can affect language learning such as motivation, attitude, anxiety (Yokochi, 2003; Henter, 2014). One of the key factors contributing the success of second or foreign language learning that has been broadly recognized is motivation (Dornyei, 1998; Norris; 2001). Then, one factor that can affect motivation is also investigated namely self-efficacy Bandura (1993). Further, for over two decades, researchers such as Sternberg (1998), Vandergrift (2005) also concerns on a factor affecting second language environment such as metacognition. It can be seen in reading activity when the students are trying to comprehend the text. This metacognition has important role in reading comprehension Flavell (1979). In relation to these phenomena, the researcher conducts a research on reading skills related to those important factors such as metacognitive awareness, self-efficacy and motivation.

In the context of EFL learning, Richard and Renandya (2002) state that reading receives a special focus in which many foreign language learners often have reading as one of the most important goals. It is important to be mastered by EFL learners to achieve their reading ability to read in a foreign language. By reading a written text, the learners have sources to get information and pleasure especially for their academic purposes. As claimed by Grabe (1991) reading is one of the important skills for second language learners in academic context. Having reading skills will ease students to gain successful in their academic. 
Relevant to the idea of reading, the prior purpose of reading is for comprehension. Goldenberg (2001) states the main goal for reading is comprehension. It is the ability to go beyond the words, to understand the ideas in a text and the relationships that exist between those ideas (McNamara, 2007). In addition, according to Torgesen (2000), reading comprehension is thus a cognitive, motivational and affective activity. Thus, this present research focuses on the reading comprehension which is related to language learning strategy and other factors such as motivation and self-efficacy.

More specifically, the importance of the reading skills in academic contexts has made it imperative for second language researchers to find out how students can be helped to deal with academic reading and writing tasks. However, a study done by Snow (2002) found out that many learners have difficulties in understanding what they read especially academic texts. In this case, language teachers have an important role in helping their students in learning. The teachers need to monitor the students' development such as motivating students to achieve better. Some studies such as (Young \& Fry, 2008; Li, 2013) revealed that students can be more successful by being aware of their metacognition.

Metacognition can be defined as the activity of monitoring and controlling one's cognition Ormrod (2004). It is about what we know about our cognitive processes and how we use these processes in order to learn and remember. Then, Schraw \& Dennison (1994) classify metacognition into two subcomponents that are metacognitive knowledge and metacognitive regulation. Metacognitive knowledge or knowledge about cognition is the knowledge that can be facilitating the reflective aspect of metacognition included declarative knowledge, procedural knowledge and conditional knowledge. Furthermore, Schraw (1998) mentions that knowledge of cognition refers to what individuals know regarding their own mental processing and includes declarative, procedural and conditional awareness; that are knowing about things, knowing the way to do things, and knowing about the reason why and the opportunity to do things.

On the other hand, metacognitive regulation or regulation of condition is a number of sub processes that facilitate the control of aspect learning. Regulation of cognition refers to all the actions the learners take in order to control their learning and involves skills in planning, monitoring and assessing their own progress in learning. It is also supported by Jacobs \& Paris (1987) who define metacognitive regulation into three essential skills namely planning, monitoring, and evaluating.

According to Phan (2006) metacognitive has been understood to play an essential part in achieving comprehension. Hence, the students need to be aware with their metacognition that leads students to have metacognitive awareness. As proposed by Flavell (1979) metacognitive awareness appears to be particularly useful in many tasks related to language use. The learners' reflection on how they go about solving learning tasks and their identification of strategies to fulfill a task not only to facilitate learning, but also to make learning better. Metacognitive awareness involves the awareness of whether or not comprehension is occurring, and the conscious application of one or more strategies to correct comprehension (Baumann, Jones, \& Seifert-Kessel, 1993).

Another factor affecting reading comprehension is self-efficacy. As defined by Bandura (1997) self-efficacy can be defined as people's judgments to determine how people feel, think, motivate themselves and behave. The people can directly motivate themselves because they believe in their abilities. Studies found that self-efficacy can contribute to students' achievement (Rahemi, 2007; Ghonsooly \& Elahi, 2011; Kargar \& Zamanian, 2014). Rahemi (2007), for instance, explored the humanities students' English self-efficacy beliefs and examined the contributions they make to their EFL achievements. The result shown that the humanities students had a low English self-efficacy, thus, it can affect negatively to their beliefs about their own academic ability as foreign language learners.

Motivation is also significant element that can influence language learners. An important factor that can affect language learning is motivation (Gardner, 1985; Dornyei 2001). As proposed by Brown (2007) motivation as the extent to which students make choices about goal to pursue and the effort learner will devote to the pursuit. Motivation can be classified into two types that are extrinsic and intrinsic motivation. As proposed by Brown (2007) extrinsic motivation is the motivation that is 
carried out from outside and beyond the self. By this motivation, the students tend to do something due to rewards such as prizes, grades or money. On the other hand, intrinsic motivation can be described as behaviors that aimed at bringing certain feelings of competence and self-determination.

Some previous researches such as Pintrich (2003) have discussed on how motivational and cognitive processes interact and how those factors affect achievement outcomes. They found that motivational variable such as self-efficacy and intrinsic motivation can predict students' achievement such as in reading abilities or other language skills.

Based on the discussion above, the researcher can find the gap from the previous studies. Those previous studies have focused on metacognitive strategy use that examined the readers' awareness of strategies during the reading process. In this present research, the researcher investigates students' awareness of metacognition.

In this present research, the researcher concerns on the studies of the metacognitive awareness, motivation and reading comprehension. It investigates the model of relationship between those variables. The general question can be analyzed into two sub-questions that are as follows: 1 . How is the path of the correlation between students' metacognitive awareness, self-efficacy, motivation and their reading comprehension?, 2.How is the path of the correlation between students' metacognitive awareness, self-efficacy and their motivation?

\section{METHODS}

This research is intended to examine the model of the relationship between metacognitive awareness, self-efficacy, motivation and students' reading comprehension. This research also employed correlation design to see the correlation between the variables involving path analysis (Gall et. al., 2007). Then, a path analysis design is used to see the model of the relationship between the variables. The research is proposed to explain the students' reading comprehension in relation to their metacognitive awareness, self-efficacy and motivation. Moreover, the researcher described the result of this data in from the statistical result of the data to see the relationship between those variables. Then, the researcher investigated the modeling relationship between those factors and EFL reading comprehension.

Based on the research problems, the purpose, and the hypothesis, there are three variables used in this present research: three independent or exogenous variables and one dependent or endogenous variable. Metacognitive awareness, self-efficacy and motivation are independent variables and students' reading comprehension is dependent variable.

The population consists of eight classes in total. However, the accessible classes that can be observed were five classes with 90 students in total. Since the researcher used the classes which were randomly chosen, hence the simple random sampling was required. The students were arranged in group as their original class placement.

This study used questionnaires and a test to collect the data. There were three questionnaires and one test. The questionnaires in this study were Metacognitive Awareness Inventory (MAI) to elicit the data related to the students' metacognitive awareness, Reading Self-efficacy questionnaire and Motivation for Reading Questionnaire (MRQ) as the instrument to collect the data related to the students' motivation. The three questionnaires were adapted from previous research that has been generalized as the research need. The questionnaires were constructed based on the theory used. Besides, the researcher also considered and omitted the items of the questionnaire that is not in line with the research objectives. While the test of EFL reading comprehension was used to measure the students' reading comprehension. 


\section{RESULTS AND DISCUSSION}

Based on the result of simultaneous testing, the hypothesis formulated from the two layers of multiple regression of the path model shows that the first layer does not show the significant contribution toward dependent variable. On the other hand, the second layer is proved to have the significant contribution toward dependent variable. Additionally, based on the result of the partial analysis testing of the path, it is shown that all independent variables in the first layer do not have significant correlation. Then, in the second layer, there is only one significant correlation toward dependent variable. Though, the first proposed pattern does not show insignificant, the $\mathrm{X} 2$ variable (self-efficacy) shows the biggest contribution of the path diagram toward EFL reading comprehension which is mediated by motivation.

The result of this study does not have significant empirical contribution evidence to prove the direct correlation of metacognitive awareness (X1) toward EFL reading comprehension (Y). This finding is also in line with Meniado (2016) who found out that there is no significant relationship between the students' use of metacognitive reading strategies and their reading comprehension performance. It means that the use of metacognitive reading strategies does not positively affect the reading comprehension performance of the students.

The next variable is self-efficacy which refers to the individual beliefs about his or her capability to do an action on his or her life. Bandura (1997) states that self-efficacy is people's judgments to determine of how people feel, think, motivate themselves and behave. It is clarified to be influential factor in reading and has a critical influence on reading achievement. However, the result of this study shows that there is insignificant empirical evidence to prove the direct correlation of self-efficacy toward EFL reading comprehension. The finding is in contrast with the studies of Pajares (1996) and Schunk \& Zimmerman (2007) confirmed that students with high self-efficacy for performing a task work harder, persist longer, participate more readily, and achieve at higher levels. It is also supported by Pressley \& Gaskins (2006) found out that high self-efficacy is important for students' academic since it becomes a causal factor in future academic success through motivating students in maximizing their strength and minimizing their weakness. Furthermore, the findings of Musthofiyah (2015) found out that reading self-efficacy was the dominant factor with 39.4\% affects EFL reading comprehension. Those findings show that of self-efficacy can affect EFL reading comprehension. Moreover, the path correlation between self-efficacy and motivation in second layer is found to be significant. The result of this study shows that there is significant correlation between self-efficacy and motivation.

The third factor affecting EFL reading comprehension in this research is motivation. It refers to a person's desire to do a task. It is said to be a powerful factor in facilitating reading comprehension. However, the result of this study does not show the significant empirical evidence to prove the direct correlation of motivation toward EFL reading comprehension. The finding is in contrast with the works of Guthrie (2008), Middleton (2011) found out that personal motivation and interest significantly affects reading comprehension. Student's perception about their reading abilities and their motivation to read correlates with reading comprehension and reading ability (Guthrie, 2008). Another research by Cahya (2015) also found out that EFL proficiency is initiated by motivation and mediated by attitude.

Regarding to the pattern found in this research, the factors that should be maximized are selfefficacy then motivation and metacognitive awareness. Though, the results do not show the significant correlation toward students' comprehension, these three factors also have contribution for their reading. On the other side, reflected from the interview result, the factors that need to be maximized are motivation then metacognitive awareness and self-efficacy.

\section{CONCLUSION}

Refers to the research constructed in this study, the result shows that there is no significant correlation between students' metacognitive awareness, self-efficacy, motivation and their reading comprehension. However, the model of the correlation in the second pattern proposed in this study was proven significant. Others, the contribution of students' metacognitive awareness, self-efficacy 
and motivation contribute to EFL reading comprehension is $2.5 \%$. For the clear description of the result can be examined as follows.

The result of the analysis in this study proves that the regression model derived from the first proposed path is proven insignificant to the independent variable. On the other hand, the result of the regression model of second proposed path in this study is proven to have significant contribution to the independent variable. Besides, as the result of individual testing of their partial correlation, it is revealed that some paths of the independent variables to the dependent variables do not show significant correlation.

Based on the summary of path contribution, it is inferred that the dominant path which contributes the most toward EFL reading comprehension is X2 mediated by X3 or the variable of self-efficacy and mediated by motivation. The next dominant contribution in the path is X3 to Y or direct path of motivation toward EFL reading comprehension. The last dominant contribution is the path X1 and X2 mediated by X3 toward Y or metacognitive awareness and self- efficacy mediated by motivation toward EFL reading comprehension.

The effective path for the EFL reading comprehension comes from self-efficacy mediated by motivation. Though, it does not show the significant relationship toward EFL reading comprehension, this path is proven to have the most contribution in the path diagram. While, in the second layer of the proposed pattern in this study shows that there is significant relationship between self-efficacy and motivation. When it is mediated by motivation, it gives the dominant contribution toward EFL reading comprehension in the path diagram. Based on this result, the implication towards teaching and learning especially for EFL student is that students' motivation is very important and they should be guided to be self-efficacious student. Once they have a high self-efficacious, they will be motivated for their learning due to its effect on their belief and their desire to do the task. Hopefully, by emphasizing these two factors, they can do well in reading comprehension.

Based on the result of the study, it is important to present several suggestions in the present study. Theoretically, the result of this study can be considered as the basis for the teacher and lecturer in their teaching of reading. The result shows that the three selected factors in this research do not show the significant contribution towards students' reading comprehension. In this case, the result is not in line with the theories of those three factors namely metacognitive awareness, self-efficacy and motivation. Hence, the findings of this research can be reflected as an additional perspective on the existing theories. In relation to the theories, the reading processes within reading comprehension should be considered behind those three factors influencing reading comprehension. The three factors be triggering factor to increase reading comprehension processes which cover background knowledge, vocabulary and reading strategies as well. Further, the findings also figure out that the biggest contribution to EFL reading comprehension that comes from self-efficacy which is mediated by motivation. Moreover, the result of this study can be used as an additional reference, topic discussion, and research material for the future researchers.

\section{REFERENCES}

Baumann, J. F., Jones, L. A., \& Seifert-Kessel, N.1993. Using Think, A louds to Enhance Children's Comprehension Monitoring Abilities. The Reading Teacher, 47(3), 184-193.

Bandura, A. 1993. Perceived self-efficacy in cognitive development and functioning. Educational Psychologist, 28,117-148.

Bandura, A. 1997. Self-efficacy in Changing Societies. Cambridge: Cambridge University Press.

Bandura, A. 2006. Guide for constructing self-efficacy scales. In F. Pajares \& T. Urdan (Eds.) Selfefficacy beliefs of adolescents. Greenwich, CT: Information Age Publishing.

Brown, H. D. 2007. Teaching by Principles: an interactive approach to language pedagogy ( $3^{\text {rd }}$ ed.). New York: Pearson Education.

Cahya, P. 2015. Modelling Relationship among Selected Affective Factors and EFL proficiency of College Students. Unpublished Thesis. Malang: State University of Malang. 


\section{Nuriyatul Hamidah}

Dornyei, Z. 1998. Motivation in Second and Foreign Language Learning. Journal of Cambridge: Language Teaching, 31 (3), 117-135.

Dornyei, Z. 2001. Teaching and Researching Motivation. London: Pearson Education Limited.

Flavell, J. H. 1979. Metacognition and Cognitive Monitoring: A New Area of CognitiveDevelopmental Inquiry. American Psychologist, 34, 906-911.

Gall, M. D., Gall, J.P., \& Borg, W. R. \&. 2007. Educational Research: An Introduction. (8 ${ }^{\text {th }}$ Edition). New York: Pearson.

Gardner, R. C. 1985. Social Psychology and Second Language Learning: The Role of Attitudes and Motivation. London: Edward Arnold Publishers.

Ghonsooly, B. \& M, Elahi. 2011. Learners' Self-efficacy in Reading and its relation to Foreign Language Reading Anxiety and Reading Achievement. Journal of English Language Teaching and Learning Year, 53 (217).

Goldenberg, C. 2011. Reading Instruction for English Language Learner. Handbook for Reading Research. 4, 684-710.

Grabe, W. 1991. Current developments in second language reading research. TESOL Quarterly, 25(3), 375-406.

Guthrie, J. T. 2008. Reading motivation and engagement in middle and high school: Appraisal and intervention. In J. T. Guthrie (Eds.), Engaging adolescents in reading (pp. 1-16). Thousand Oaks, CA: Corwin Press.

Henter, R. 2014. Affective Factors Involved in Learning a Foreign Language. Procedia-Social and Bihavioral Sciences, 127, 373-378.

Jacobs, J. E. \& Paris, S. G. 1987. Children's' Metacognition about Reading: Issues in Definition, measurement and instruction. Educational Psychologist, 22: 255-278.

Kargar, M \& Zamanian, M. 2014. The Relationship between Self-Efficacy and Reading Comprehension Strategies Used by Iranian Male and Female EFL Learners. International Journal of Language Learning and Applied Linguistics World (IJLLALW), 7 (2), 313-325.

Meniado, J. C. 2016. Metacognitive Reading Strategies, Motivation, and Reading Comprehension Performance of Saudi EFL Students. English Language Teaching journal Canadian Center of Science and Education, 9 (3): 117- 129.

McNamara, D. S. 2007. Reading Comprehension Strategies: Theories, Interventions and Technologies. Mahwah: Lawrence Erlbaum Associates.

Musthofiyah, U. 2015. A Model of Reading Comprehension of EFL College Learners Observed from Reading Self Efficacy, Reading Attitude and Reading Frequency across Gender. Unpublished Thesis. Malang: State University of Malang.

Norris-Holt, J. 2001. Motivation as a contributing factor Second Language Acquisition. The Internet TESL Journal, 7 (6): 1-8.

Ormrod, J.E. 2004. Human Learning. New Jersey: Pearson.

Pajares, F. 1996. Self-efficacy beliefs in academic settings. Review of Educational Research, 66(4), 543-578.

Phan, N. 2006. Effective reading. Retrieved from http://www.asian-efljournal.com/pta_october_06_np.php.

Pintrich, P. R. 2003. A Motivational Science perspective on the Rule of Students Motivation in Learning and Teaching Context. Journal of Educational Psychology. 95, 667-686.

Pressley, M., \& Gaskins, I. 2006. Metacognitively competent reading comprehension is constructively responsive reading: how can such reading be developed in students? Metacognition Learning, 1(1), 99-113.

Rahemi, J. 2007. Self-efficacy and Iranian Senior High School Students Majoring in Humanities. Novitas-ROY AL (Research on Youth and Language), 1(2), 98-111.

Rahimi, M. \& Katal, M. 2012. Metacognitive Strategies Awareness and Success in Learning English as a Foreign Language: An Overview. Procedia Social and Behavioral Sciences. 31, 73-81. 
Schunk, D. H., \& Zimmerman, B. J. 1997. Social origins of self-regulatory competence. Educational Psychologist, 32(4), 195-208.

Schraw, G. \& Dennison, R. S. 1994. Assessing Metacognitive Awareness. Contemporary Educational Psychology. 19, 460-475.

Schraw, G. 1998. Promoting General Metacognitive Awareness. Kluwer Academic Publishers Instructional Science 26; 113-125.

Snow, C. 2002. Reading for understanding: Toward an R\&D program in reading comprehension. Santa Monica: Rand Education.

Sternberg, R. J. 1998. Metacognition, Abilities and Developing Expertise: What Make an Expert Student? Instructional Science, 26, 127-140.

Torgesen, J. K. 2000. Individual Differences in Response to Early Intervention in Reading: The Lingering Problem of Treatment Resisters. Learning Disabilities Research and Practice, 15 (1): 5564.

Richards, J. C and Renandya, W. A. 2002. Methodology in Language Teaching. an Anthology of Current Practice. Cambridge: Cambridge University Press.

Vandergrift, L. 2005.Relationship Among Motivation Orientation, Metacognitive Awareness and Proficiency in L2 Listening. Applied Linguistics, 26, 70-89.

Yokochi, L. 2003. Affective Factors in Second Language Acquisition: A critical Review of the Literature. Unpublished Thesis. Morgantown: West Virginia University.

Young, A., Fry, J. D. 2008. Metacognitive Awareness and Academic Achievement in College Students. Journal of the Scholarship of Teaching and Learning, 8 (2): 1-10. 